\title{
BASAL BOLUS INSULIN REGIMENS FROM DIAGNOSIS IMPROVE HONEYMOON PERIOD COMPARED WITH TWICE DAILY MIXED INSULIN REGIMENS
}

\author{
A. Gupta ${ }^{1}$, T. Randell ${ }^{2}$ \\ ${ }^{1}$ Paediatrics, ${ }^{2}$ Paediatric Endocrinology, Nottingham Childrens Hospital, Nottingham, UK
}

Background: In the UK at present, different centres use different insulin regimens for paediatric patients at diagnosis of Type 1 Diabetes. Some centres start all children on basal bolus or multiple dose injection (MDI) regimens, whereas others still use twice daily (BD) mixed insulins in certain age groups, partly because of difficulties in supporting insulin administration in school. Since 2008, all children newly diagnosed with diabetes attending Nottingham Children's Hospital have been started on a MDI regimen, regardless of age. We aimed to assess whether either of these insulin regimens produced better honeymoon $\mathrm{HbA} 1 \mathrm{Cs}$ and duration of honeymoon period.

Methods: A retrospective analysis of $\mathrm{HbA1C}$ and duration of honeymoon period in children started on MDI regimens compared with those started on BD regimens, looking at all children and young people registered with the Nottingham Paediatric Diabetes Service in Dec 2010. Honeymoon was defined using Insulin Dose Adjusted for A1C ie $\mathrm{HbA1C}+(4 \mathrm{x}$ total daily dose insulin in units/kg/day) as $<9$.

Results: There were no differences in sex, age distribution or initial education given between the BD regimen group $(n=104)$ and the MDI group $(n=106)$. At 6 months, $45 \%$ of children on the BD regimen were still honeymooning, vs $75 \%$ on MDI ( $<<0.001)$. At 12 months, this had dropped to $23 \%$ in the BD group vs $42 \%(\mathrm{p}<0.02)$ in the MDI.

Conclusions: It would appear that MDI regimens from diagnosis give a significantly more prolonged honeymoon period than $\mathrm{BD}$ mixed insulins. 